\title{
Numerical simulation of progressive debonding in notched steel beams strengthened by CFRP plate
}

\author{
Cheng Geng \\ School of Business Administration, Xinyang Agriculture and Forestry University, Xinyang 464000, China
}

ABSTRACT: CFRP repairing is an effective way of repairing or strengthening notched steel beams. However, the debonding failure of CFRP repairing reduces the effectiveness of this reinforcement technique. The CFRP repairing debonding is the most dangerous failure mode to reduce the efficiency of CFRP repairing. In this paper, the surface based cohesive model and the finite element method are used to study the initiation and progression debonding failure of progressive debonding in notch damaged steel beams strengthened by CFRP plate. The effect of the patch length on the debonding is studied in this paper which can be used to optimize the geometrical properties of the composite patch.

KEYWORD: CFRP plate; Strengthened; Steel beams; Debonding ; Notch; Finite element method; Surface based cohesive

\section{INTRODUCTION}

CFRP repairing has been confirmed to be a good way to upgrade and retrofit the service time of steel structures [1-14]. Previous studies have proved that the load-carrying capacity of steel structures is dramatically improved by adhesive bonded patching [15-17].

However, CFRP repairing debonding is a failure mode which should be paid attention to during the repairing studies. Researchers have agreed that the adhesive repairing bonding is the most dangerous point in steel strengthening repairing because of the high stress concentration [17-19]. A few FE models were used to study the stress concentration effects that located in the steel beam [2, 17, and 19]. Teng [20] studied the CFRP repairing debonding failures of steel beams and conducted both theory study and experiments to study the notch damaged steel beams strengthened by CFRP plate [21].

However, little research is conducted to study the progressive debonding in notch damaged steel beams strengthened by CFRP. In this paper, the FE method is adopted to study both the initiation and the progression of the debonding failure of the notched steel beams strengthenedby CFRP when the steel is applied to an incremental four points bending load. And the effect of the patch length on the debonding property is studied. The results can give some suggestions to slow down the debonding propagation.

\section{GEOMETRICAL MODEL}

The model of the retrofitted beam considered is as in Fig. 1. The steel beams have the following material properties: Elastic constant $E_{p}=2100 M p a$; Poisson ratio $v=0.33$. And the steel is considered to be perfect elasto-plastic: Yield stress $\sigma_{s}=345 \mathrm{MPa}$

The elastic properties of the reparing patch are shown as follows:

$$
\begin{aligned}
& E_{1}=2100 M p a \quad, \quad E_{2}=10 M p a, E_{3}=10 M p a ， \\
& G_{12}=3700 M p a \quad, \quad G_{13}=26500 M p a \quad \text {, } \\
& G_{23}=26500 \mathrm{Mpa} \quad, \quad v_{12}=0.3 \quad, \quad v_{13}=0.006 \text {, } \\
& v_{23}=0.006
\end{aligned}
$$



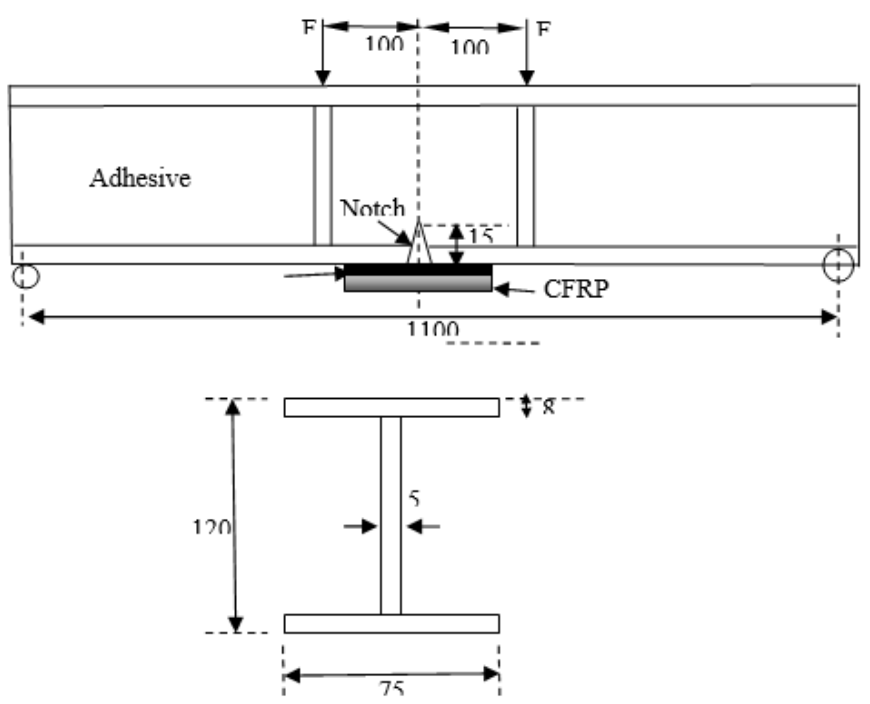

Fig.1 retrofitted beam model.

\section{FINITE ELEMENT MODELING}

The FE model is used in the study with ABAQUS. The debonding of patch and beam is studied by the Surface-based cohesive method in ABAQUS. So the FE model consisted of only two subsections: beam and the composite patch. The contact constraint is created between the beam and the composite patch. The web in the mid-span region of the steel beam studied includs four full-depth stiffeners on the two sides. Each stiffener that contact with the beam were tied to the top flange with three edges. The shell element S4R is used to model both the steel beam and the CFRP reparing plate .Fig. 2 shows the mesh of the steel beam and repairing patch.

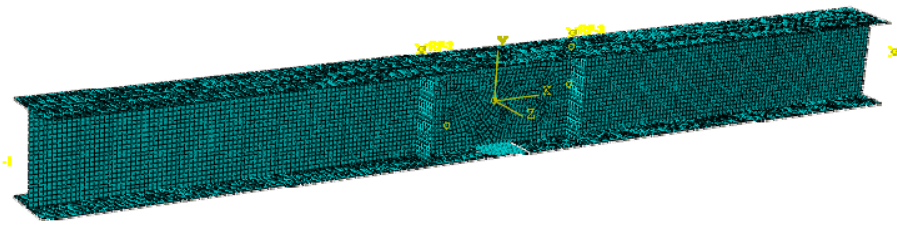

(a)

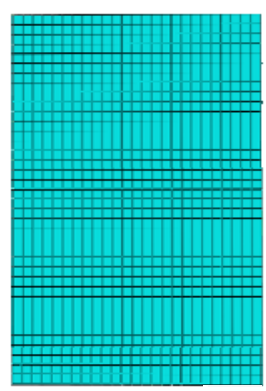

(b)

Fig. 2 (a) mesh of the steel beam (b) repair patch.

\section{DEBONDING FAILURE ANALYSIS}

In this research, Surface-based cohesive parameters are selected as follows: strength of tensile (30 MPa), elastic constant of tensile (8 GPa), shear con$\operatorname{stant}(2.5 \mathrm{GPa})$ mode-I fracture energy(0.06 $\mathrm{N} / \mathrm{mm}$ ).A typical equivalent stress plot of beam is shown in Fig. 3.

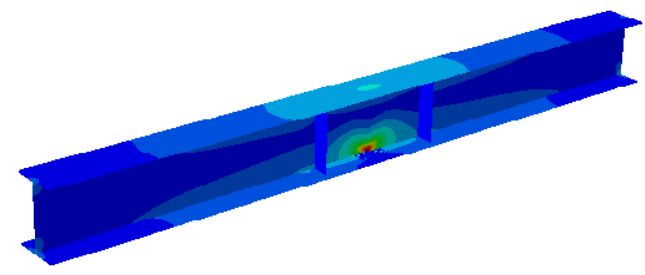

Fig. 3 Typical equivalent stress plot

To highlight the effect of the length of the patch, four cases are considered: No reparing, 50mm, $100 \mathrm{~mm}, 150 \mathrm{~mm}$. And the Load-deflection curves obtained are shown in

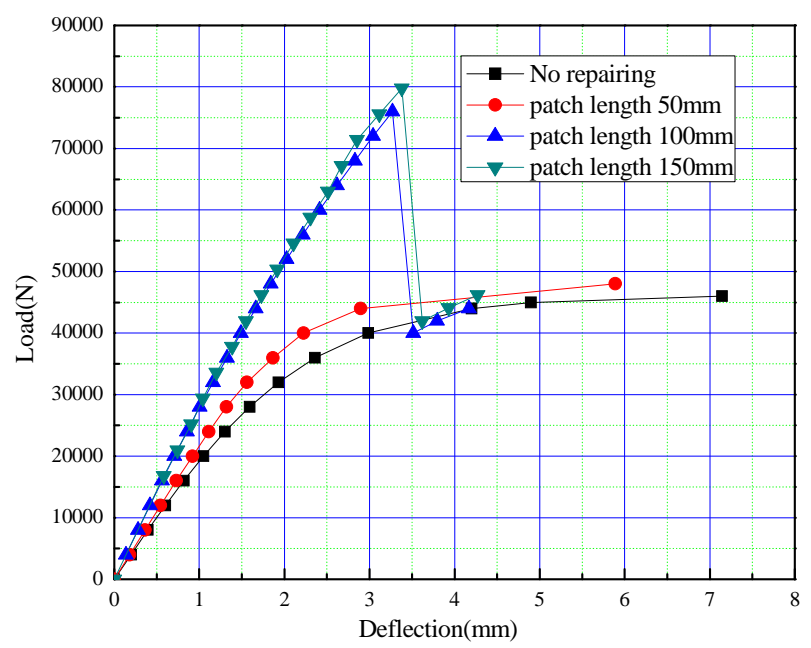

Fig.4 Load-deflection curve

As we can see from Fig.4, the curve of No repairing patch length $50 \mathrm{~mm}$ are very close which means the repair effect is not obvious when the patch length is relatively short, the repair effect is not obvious. And when the patch length increase to $100 \mathrm{~mm}$, it increased the loads significantly which is almost twice of the No repairing. When the patch and beam starts to get debonded, the debonding grows very fastly and the load drops dramsticaly and soon converg with the case of no repairing plate which means it reduces the effective reparing area of the patch significantly . 


\section{DISCUSSION AND CONCLUSIONS}

In this study, the FE method and the surface based cohesive model is adopted to study the initiation and progression CFRP reparing debonding failure of progressive debonding in notch damaged steel beams strengthened by CFRP plate. Effect of the patch length on debonding is studied. We can obtain some conclusions throuth this studyas following:

1 . The repair effect is obvious only when the repairing patch gets to a certain value.

2. The repair can increased the loads significantly compared with the No repairing case.

3 . When the patch and beam starts to get debonded, the debonding propagates very fast and converges soon with the case of no repairing plate.

\section{ACKNOWLEDGEMENTS}

The author is grateful to Dr.Rong Zhang in Guangdong University of Technology for very helpful disscussions and Dr.Lu jie for English revisions.

\section{REFERENCES}

[1] Dawood, Rizkalla S, Sumner E. Fatigue and rloading behavior of steelconcrete composite flexural member strengthened with highmodulus CFRPmaterials. J Compos Constr 2007; 11(6):659-69.

[2] Hollaway, Cadei J. Progress in technique of grading metallic structure with advanced polymer composite. Prog Struct MatEng 2002; 4 (2):131-48.

[3] Deng, Le MMK. Adhesive bond in steel beam strengthened by CFRP.Proc Inst Civil Engering Structure Build 2009; 162(4):241-9.

[4] Colombi P, Poggi C. An experital and numerical study of the static property of reinforced by pultruded CFRPstrips. Compos B: Eng 2006; 37(1):64-73.

[5] ASCE. Report for America’s infrastructures. Restno, VA, US: American's Society of Civil Engineer; 2005.

[6] Lenwari, Thepchatri T, Albrecht. Debonding strengthen of steel beamsstrengthened with CFRP plate. J Composite Construre2006; 10(1):69-78.

[7] Deng, Lee MK. Adhesive bonding in steel beam strengthened withCFRP.Structure Build 2009; 162:241-9.

[8] Sallam HM, Ahmad SE, Baday AM, Mamdouh W. Evaluation ofsteel Ibeamsstrengthened by various platingmethods. Advanced Structure Eng2006; 9(4):535-44.

[9] Colobi P, Pogi C. An experimenta and numerical study of thestatic behaviors ofsteel beams reinforced with pultruded CFRP strip. Composite B2006; 37(1):64-73.

[10] Yousef MA. Analytical predictions of thelinear and nonlinear behavious ofsteel I beam rehabilitated with FRP sheet. Eng Structures 2006; 28(6):903-11.

[11] Sen R, Liby L, Mulins G. Strengthening steelbridge sections with CFRPlaminates. Composite B 2001; 32(4):30922.

[12] Benachur A, Benyocef S, Tounsi A, Ada bedia EA. Interfacial stresses analysisof steel beam reinforced by bonded prestressed FRPplates. Eng Structure2008; 30(11):3305-15.
[13] Deng, Lee MK, Li S. Flexural strengthes of steelconcrete composite beamsreinforced with a prestressed CFRPplates. Construre Build Material 2011; 25(1):379-84.

[14] Linghof D, Haghai R, Al-Emrani M. Carbonfibre composite of strengthening steel structure. Thin Wall Structure 2009; 47(10):1048-58.

[15] Buykozturk O, Gunes O, Karca E. Progresses on understanding debondingproblems in reinforced-concrete and steelmembers strengthened with FRPcomposites. Construre Build Material 2004; 18(1):9-19.

[16] Teng JG, Yu T, Fernado D. Strengthening ofsteel structure with fibre-reinforced polymer composite. J Construre Steel Res 2012; 78:131-43.

[17 Smith ST, Teng JG. Interfacial stress in platedbeams. Eng Structure2001; 23:857-71.

[18]J.G. Teg, D. Fernando, T. Yua. Finite-element modelling of debond failures in steel beam.

[19] Nozaka K, Shield CK, Hajar JF. Effective bond-length of carbonfiber reinforcedpolymer stripsbonded to fatigued bridge I-girders. J Bridge Enger 2005; 9(4):304-12.

flexurally strengthened with CFRP laminates, Engineering Structures 86 (2015) 213-224

[20] Jun Deng, Yonghui Ja, Hengzhog Zheng. Theoreticalexperimental study on notchsteel beams strengthened with CFRPplate. Composite Struct 136 (2016) 450-459.

[21] Nozaka K, Shild CK, Hajar JF. Design ofa test specimen toassess the effectivebond length of carbon-fiber reinforced polymer strip bonded to fatigued-steel bridge girder. J Composite Constr2005; 10(2):195-205. 